\title{
Article
}

\section{Environmental Exigencies and the Efficient Voter Rule}

\author{
David A. Anderson $(1)$ \\ Department of Economics and Finance, Centre College, 600 W. Walnut St., Danville, KY 40422, USA; \\ anton42@adelphia.net
}

Received: 15 October 2020; Accepted: 12 November 2020; Published: 17 November 2020

\begin{abstract}
Externality problems hinder solutions to existential threats, including climate change and mass extinction. To avert environmental crises, policymakers seek mechanisms that align private incentives with societal exigencies. Successful solutions bring individuals to internalize the broad repercussions of their behavior. In some cases, privatization, Coasian bargaining, or Pigouvian taxes effectively place the weight of externalities on the relevant decision makers. Yet, the available remedies often fail to provide satisfactory outcomes, and inefficiencies persist in the markets for energy, transportation, and manufactured goods, among others. This article explains how a simple voting mechanism can achieve socially optimal decisions about many of the innumerable externality problems that remain.
\end{abstract}

Keywords: externalities; social cost; environmental protection; efficient voter rule

\section{JEL Classification: G50}

\section{Introduction}

Private decisions about environmental protection are fraught with externality problems, while public decisions are vulnerable to special interests and incomplete information. Trends in resource degradation and climate change continue at alarming rates despite considerable attention from economists over the past century. Coase (1960) advanced the theorem that private bargaining will achieve socially optimal resolutions to externality problems when property rights are clearly defined and transaction costs are negligible. The bargaining approach, like several others discussed below, works under some circumstances and fails under others. Progress toward efficiency on environmental fronts requires the identification of additional, complementary means of addressing externalities. This article advances voting as a straightforward approach to efficient decision-making that is useful in situations not well served by other approaches. Like Coase's solution of bargaining, voting is a familiar practice for other purposes; what is novel is substantiation that under appropriate conditions, the practice yields socially optimal resolutions to pressing policy dilemmas.

Externality problems arise when some of the effects of a decision are felt beyond, or external to, the person making the decision. In that case, the decision maker's private benefit or cost-that which is internalized by the decision maker-differs from the benefit or cost for all of society. Social efficiency is achieved when actions are carried out if and only if the benefit to society exceeds the cost to society, thereby maximizing the net gains for society. Socially inefficient decisions about environmental protection and resource conservation are expected when the private cost falls between the private benefit and the social benefit. Consider a $\$ 100$ expenditure on tree seedlings that would provide a $\$ 50$ benefit to the consumer by increasing the value of the consumer's property, and a $\$ 200$ benefit to society by providing a carbon sink and beauty for passersby to enjoy. The consumer would decide against the expenditure because $\$ 50<\$ 100$, while the socially optimal decision would be to purchase the seedlings because $\$ 100<\$ 200$. The consumer would make the best decision for society if the consumer 
internalized the $\$ 150$ benefit the purchase conferred on others. To that end, policymakers seek to align private incentives with broader repercussions, such that decision makers weigh the social marginal benefit of each decision against the associated social marginal cost. Legislators in the United States and elsewhere currently establish environmental policies using deliberative processes whose influences can depart from that criterion for allocative efficiency (EPA 2020). On a global scale, the private disregard of external costs can fuel environmental crises including air and water pollution and climate change (Zhang and Wang 2017).

Buchanan and Tullock's (1962) seminal work shows how voting leads to outcomes in the public interest. Anderson (2011) explains how voting can elicit efficient decisions on topics ranging from community requirements for septic systems to wine consumption by a group that is splitting the check at a restaurant. The present article expands on those findings and highlights the power of a referendum - a simple up or down vote on a contemplated action-to navigate decisions about externalities and maximize the resulting net benefits for society.

The social efficiency of a referendum on environmental policy can be summarized by what we shall refer to as the efficient voter rule: A vote among fully informed parties on the provision of a uniformly distributed positive externality at a given cost per party will reveal the socially efficient outcome, regardless of the amount of the externality attributable to each party. The rule applies equivalently to the abolishment of negative externalities.

The efficient voter rule extends to externality problems beyond environmental issues. For example, the rule suggests that when the citizens of Tuscon, Arizona, voted on whether to use cameras to detect drivers who failed to obey traffic signals (Smith 2015), the outcome was socially efficient. Likewise, decisions about whether to mandate vaccines during a pandemic would be efficient if citizens paid the same price for vaccines and received equivalent benefits from broad immunity. The purpose of this article is to explain how and why the rule applies to critical environmental policy decisions.

Section 2 of this article provides a review of the related literature. Section 3 explains the theoretical foundation for the efficient voter rule. Section 4 discusses further applications of the rule. Section 5 concludes the paper.

\section{Literature Review}

The previous literature on externalities offers several approaches that are effective under particular circumstances. Pigou (1932) describes how taxes and subsidies can cause decision makers to internalize negative and positive externalities, respectively. Pigouvian solutions can lead to efficient decisions, the caveat being that policymakers need full information on the marginal external cost or marginal external benefit involved in order to establish the appropriate value for the tax or subsidy. Even with full information, this solution may not lead to the optimal outcome. For instance, taxes can lead to excessive deterrence when overlapping remedies, such as litigation, benevolence, regulation, or risk burdens are in place (Viscusi 1991, p. 129). Furthermore, the application of taxes or subsidies can obscure preferable alternatives, such as options to move polluters or pollution victims to new locations when the benefit of such a move exceeds the cost.

The introduction noted Coase's (1960) finding that private bargaining can lead to efficient decisions in the face of externalities when property rights are clearly defined and transaction costs are insignificant. Anderson (2019) explains that Coasian solutions may fail in cases involving multiple victims, multiple sources, incomplete information, strategic behavior, time lags, asymmetric information, or social mores against such bargaining. Similarly, Anderlini and Felli (2006) show that common transaction costs can upset the efficiency of Coasian bargaining.

Hardin (1968) advocated private property rights to place the otherwise external costs of activities that degrade open-access land onto property owners. For similar reasons, Libecap (2009) advocates rights-based solutions such as tradable emissions permits, individual transferable quotas, and private water rights. However, all such market-based instruments rely on the ability to privatize and enforce rights to emissions or resources. It may be impossible to privatize resources such as flowing water 
or air. Ocean fisheries are among the resources that are difficult to monitor. And national forests are among the natural resources that provide public goods, such as oxygen and carbon sequestration, the benefits of which are not internalized even if the forests become private.

Economists have long understood that votes can reveal valuable information and guide socially efficient decisions. Wicksell (1958) advocates votes to select both public expenditures and taxes that are optimal for society. Musgrave (1959) explains that externalities thwart the efficiency of markets and advocates voting mechanisms to reveal consumers' true preferences. In his discussion of regulations and taxes that impose burdens on other countries, Piketty $(1996$, p. 16) describes voting as a "natural way to induce individual agents to internalize an externality". The present article shares that objective, but uses a model unlike that of other authors to explain how the virtues of voting extend to social optimality in environmental policy decisions.

\section{The Theoretical Model}

The efficiency of environmental policy depends on the incentives that drive decision makers. Let $\rho$ be the price of a product that consumers could buy to reduce their carbon footprint, such as supplemental home insulation, a windmill, an electric car, or bamboo flooring. Let $\alpha$ represent the discounted present value of the entirely private benefit from that purchase, such as the savings on utility bills achieved with added insulation or a windmill. Let $\beta$ represent the discounted present value of the benefit to society of purchasing the product.

Assuming $n$ citizens share the social benefit equally, each consumer's share of the social benefit is $\beta / n$. It is privately optimal to purchase the product if the consumer's benefit exceeds the price:

$$
\alpha+\beta / n>\rho .
$$

It is socially optimal to purchase the product if the benefit to society exceeds the price:

$$
\alpha+\beta>\rho .
$$

The private solution differs from the socially optimal solution, in that the consumer will not purchase the good even though it provides a net gain to society, if

$$
\alpha+\beta>\rho>\alpha+\beta / n
$$

Inefficiency arises from the product's external benefit,

$$
\beta-\beta / n
$$

Under conditions that include an absence of transaction costs, the citizens experiencing the negative externalities would be willing to offer consumers Coasian bribes of up to $\beta-\beta / n$ to purchase the product. However, if $n$ is large, coordination and negotiation among the affected citizens create transaction costs that generally obstruct socially efficient outcomes.

Although a fully informed and benevolent government could offer a subsidy of $\beta-\beta / n$ for purchases of the good, government authorities may have poor estimates of $\beta$ or be influenced by ulterior motives. Privatization is unlikely to lead to social efficiency because, as discussed in Section 2, the privatization of oceans, forests, and other resources affected by carbon emissions is often unrealistic or ineffective.

An alternative solution would be to hold a referendum in which each citizen would vote on whether everyone should be required to purchase the product. A simple majority would determine the outcome. Each citizen's decision on the purchase mandate hinges on a criterion that differs from the private purchase decision because the vote determines whether everyone purchases the product. A citizen's successful vote in favor of the mandate leads to a benefit to that citizen of the private savings 
plus the share of the per-capita social benefit the citizen receives from each mandated purchase times the number of purchases:

$$
\alpha+n(\beta / n)=\alpha+\beta .
$$

Hence, the benefit of voting in favor of the mandate equals the social benefit of purchasing the good, and each citizen will vote in favor if and only if that benefit exceeds the product price: $\alpha+\beta>\rho$. In other words, citizens will make the socially optimal decision. Section 4 provides a numerical example.

The result holds even if the social benefit of purchasing the product differs across citizens. For example, suppose a purchase lowers some users' carbon footprint more than others'. That would be true in the case of electric cars if some car owners were replacing cars that polluted heavily and others were replacing cars with minimal emissions. Let $B$ represent the discounted net present value of the benefits to society from a purchase by a citizen who creates high benefits, and $b$ represent the discounted net present value of the benefits to society from a purchase by a citizen who creates low benefits. Let $h$ be the number of citizens whose purchase creates high benefits, while a purchase by the remaining $n-h$ citizens creates low benefits. The criterion for a socially optimal outcome is that each citizen votes in favor of the mandate if and only if $\alpha+\bar{\beta}>\rho$, with $\bar{\beta}$ representing the mean social benefit from the product.

Whether a citizen's purchase creates high or low benefits, a successful vote in favor of the mandate gives each citizen

$$
\alpha+(h B) / n+[(n-h) b] / n=\alpha+[h B+(n-h) b] / n=\alpha+\bar{\beta} .
$$

Thus, whether their purchase creates high or low benefits, citizens will vote in favor of the mandate if and only if the criterion for social optimality is met: $\alpha+\bar{\beta}>\rho$.

Because each citizen will vote for the socially optimal outcome, a referendum yields the best decision for society regardless of how many citizens vote. It also does not matter whether the associated externalities are positive or negative. As an example of the latter, consider the decision of whether car owners should be required to have their exhaust systems checked annually for excessive emissions. In that case $\alpha$ and $\beta$ represent the private and social benefits of eliminating the negative externality of emissions, and the model as shown above demonstrates that a vote leads to the socially optimal outcome.

The efficient voter rule rests on the assumption that citizens are informed about the price of the product, $\rho$, their entirely private benefit, $\alpha$, and the equally shared social benefit they receive from each user, $\beta / n$. The socially efficient outcome is not assured if citizens lack information on their own costs or benefits. Hidden costs or benefits will similarly derail the social efficiency of Coasian bargaining and privatization. The Pigouvian approach of taxes or subsidies may be preferable if the government holds information on the associated externalities and the citizens do not know their own costs and benefits. If neither the citizens nor the government knows the relevant values, none of these approaches can assure the appropriate decision and the path to a socially efficient outcome begins with a pursuit of information. Prohibitive information costs send the question into a realm of decision making under uncertainty that is beyond the scope of this article.

\section{Discussion}

The efficient voter rule applies to a broad set of environmental exigencies. Consider a numerical example. With single-use plastics overwhelming waste systems around the world, economies must decide whether to ban plastic shopping bags. Suppose each citizen receives $\$ 200$ worth of convenience annually from the use of plastic shopping bags. Suppose also that each citizen who does not use plastic shopping bags creates two types of benefits: $\$ 50$ worth of personal pride or "warm glow" from helping the environment, and $\$ 500$ worth of avoided environmental damage, a benefit that is spread evenly among 1000 citizens. 
In this scenario, it is not socially optimal to use plastic shopping bags because each citizen's \$200 value of convenience from using the bags is less than the $\$ 550$ worth of pride and damage-avoidance to be gained by giving them up. Even so, citizens would use the bags because their $\$ 200$ private benefit would exceed their $\$ 50.50$ opportunity cost of bag use-the sum of $\$ 50$ worth of forgone pride and $\$ 500 / 1000=\$ 0.50$ in forgone environmental benefits. An externality problem arises because each citizen fails to internalize the $\$ 499.50$ worth of environmental benefits a decision against bags would confer on the 999 other citizens.

Given the opportunity to vote on an economy-wide plastic bag ban, the citizens know that their decision could affect everyone's behavior, not just their own. The citizens would each weigh their \$200 loss of convenience from the ban against their \$50 gain in pride plus their $\$ 0.50$ share of each of 1000 citizens' environmental benefits from the ban, for a total of $\$ 50+1000 \times \$ 0.50=\$ 550$. Because $\$ 200<\$ 550$, citizens would vote in favor of the ban, and the vote would achieve the socially optimal outcome.

To examine a case in which the proposed policy is not socially efficient, consider an alternative scenario in which each citizen's annual convenience from using plastic shopping bags is worth $\$ 600$. In that case, each citizen's $\$ 550$ annual benefit from a ban falls short of the $\$ 600$ cost of lost convenience. Given the opportunity to vote, citizens would weigh their $\$ 600$ loss from a ban against their $\$ 550$ benefit, and they would vote against the ban. Again, the vote would achieve the socially optimal outcome.

The viability of a voting solution depends on the cost of a referendum. It may be possible to add referendum items to the ballot for a scheduled election at a negligible cost. In the event that a referendum would require a special election involving substantial costs, the added expense might be prohibitive and an alternative solution may be preferable. Other approaches face similar considerations. As discussed in Section 2, Coasian bargaining can involve prohibitive transaction costs. Likewise, Pigouvian taxes and subsidies impose implementation costs and deadweight loss. When several contemplated approaches involve associated costs, a comparison of those costs will inform the choice among those options.

Note that the workings of the efficient voter rule are not reliant on a well-informed government. Authorities do not need to estimate the value of citizens' pride from not using plastic shopping bags or the value of citizens' convenience from using the bags. The government only needs to call a referendum. The citizens only need to know how bag use would affect them personally, which is a combination of the value of their lost pride, their convenience, and their share of the cost of everyone's environmental damage.

Myriad environmental policy decisions are well suited for voting solutions. Examples include a community's decision whether to welcome a natural gas pipeline to run through its soil (Anderson 2020). In 2020, California governor Gavin Newsom signed an executive order banning electric cars by the year 2035 (Sommer and Neuman 2020). The controversial decision was not made using a vote. To the extent that citizens are able to purchase the most basic electric cars for approximately the same price (e.g., Tesla plans to make a model available to everyone for $\$ 25,000$ by 2025), and that citizens face similar repercussions from pollution and climate change, a vote on a requirement that every car be electric would lead to a socially optimal outcome. The same is true for votes on mandates for solar panels, limits on deforestation, taxes on carbon, and regulations on lawn chemicals.

Votes could lead to efficient decisions about participation in environmental agreements as well. The United States withdrew from the Paris Agreement on climate change, while a majority of Americans preferred participation (Marlon et al. 2017). If an agreement would place a similar burden on citizens in terms of its influence on lifestyle, taxes, and product prices, and the agreement would provide uniformly distributed benefits by preventing climate change and offering every citizen a viable living environment, the efficient voter rule applies. Making any such decision with a mechanism that brings citizens to internalize the repercussions of their behavior serves the goal of allocative efficiency and reveals interests of the citizenry that legislators may not fully comprehend. 
Modern practice demonstrates the viability of voting to reach decisions about environmental issues. In 2020, U.S. voters addressed topics including the reintroduction of gray wolves in wilderness areas and requirements that electric utilities obtain half of their energy from renewable sources (Lohan 2020). Other examples include referendums on nuclear power in Japan, Germany, Italy, Switzerland, and Sweden (Obe 2012; Cyranoski 2001). The widespread use of voting to make environmental decisions indicates that the associated costs are manageable, and the efficient voter rule speaks to the desirability of the resulting outcomes.

Voting is not the best approach for every situation. Some decisions involve costs or benefits for voters that they do not understand despite ambitious informational campaigns. Policies with inordinate benefits, externalities or abatement costs for a subset of the population are better addressed by alternative processes. For example, if a minority of voters would experience substantially higher benefits or costs from a decision than the majority of voters, the outcome could be socially inefficient. The severity of environmental problems warrants attention to an assortment of remedies that are effective in varying circumstances. The applicability of the efficient voter rule to common dilemmas makes it a noteworthy addition to existing options.

\section{Conclusions}

The prevalence of life-threatening externality problems demonstrates the need for new means of incentivizing socially optimal decisions. A vote among fully informed parties on the provision of a uniformly distributed positive externality (or on the abolishment of a uniformly distributed negative externality) at a given cost per party will reveal the socially efficient outcome, regardless of the amount of the externality attributable to each party. This efficient voter rule extends to a wide array of environmental policy decisions whose benefits and costs are shared similarly by community members. Some groups already make such decisions by vote, and the efficient voter rule can assure policymakers of socially efficient outcomes. For the many issues currently addressed with laissez-faire or authoritarian approaches, the efficient voter rule indicates that referendums could shepherd environmental policy toward better service of society's needs.

Funding: This research received no external funding.

Conflicts of Interest: The author declares no conflict of interest.

\section{References}

Anderlini, Luca, and Leonardo Felli. 2006. Transaction Costs and the Robustness of the Coase Theorem. Economic Journal 116: 223-45. [CrossRef]

Anderson, David A. 2011. A Voting Approach to Externality Problems. Journal of Economic E Social Policy 14: 50-61. Anderson, David A. 2019. Environmental Economics and Natural Resource Management, 5th ed. New York: Routledge. [CrossRef]

Anderson, David A. 2020. Natural Gas Transmission Pipelines: Risks and Remedies for Host Communities. Energies 13: 1873. [CrossRef]

Buchanan, James M., and Gordon Tullock. 1962. The Calculus of Consent: Logical Foundations of Constitutional Democracy. Ann Arbor: University of Michigan Press. [CrossRef]

Coase, Ronald H. 1960. The Problem of Social Cost. Journal of Law and Economics 3: 1-44. [CrossRef]

Cyranoski, David. 2001. Referendum stalls Japanese nuclear power strategy. Nature 411: 729. [CrossRef] [PubMed]

EPA. 2020. The Basics of the Regulatory Process. Available online: https://www.epa.gov/laws-regulations/basicsregulatory-process (accessed on 7 November 2020).

Hardin, Garret. 1968. The Tragedy of the Commons. Science 162: 1243-48. [PubMed]

Libecap, Gary D. 2009. The Tragedy of the Commons: Property Rights and Markets as Solutions to Resource and Environmental Problems. Australian Journal of Agricultural and Resource Economics 53: 129-44. [CrossRef]

Lohan, Tara. 2020. Four Environmental Fights on the 2020 Ballot. Available online: https://www.ecowatch.com/ 2020-environment-ballot-issues-2647868019.html (accessed on 8 November 2020). 
Marlon, Jennifer, Eric Fine, and Anthony Leiserowitz. 2017. Majorities of Americans in Every State Support Participation in the Paris Agreement. Yale Program on Climate Change Communication. Available online: https://climatecommunication.yale.edu/publications/paris_agreement_by_state/ (accessed on 13 October 2020). Musgrave, Richard A. 1959. The Theory of Public Finance: A Study in Public Economy. New York: McGraw-Hill.

Obe, Mitsuru. 2012. Fukushima Watch: Japan Mulls Referendum on Nuclear Power. Wall Street Journal. June 22. Available online: https://www.wsj.com/articles/BL-JRTB-12323 (accessed on 8 November 2020).

Pigou, Arthur C. 1932. The Economics of Welfare. London: Macmillan.

Piketty, Thomas. 1996. A federal voting mechanism to solve the fiscal-externality problem. European Economic Review 40: 3-17. [CrossRef]

Smith, Dylan. 2015. Red-Light Cameras Switched Off, Radar Vans Parked. Tucson Sentinel. November 5. Available online: http://www.tucsonsentinel.com/local/report/110515_red-light_cameras/red-light-camerasswitched-off-radar-vans-parked (accessed on 13 October 2020).

Sommer, Lauren, and Scott Neuman. 2020. California Governor Signs Order Banning Sales of New Gasoline Cars by 2035: NPR. Available online: https://www.npr.org/2020/09/23/916209659/california-governor-signs-orderbanning-sales-of-new-gasoline-cars-by-2035 (accessed on 13 October 2020).

Viscusi, W. Kip. 1991. Reforming Products Liability. Cambridge: Harvard University Press.

Wicksell, K. 1958. A new principle of just taxation. In Classics in the Theory of Public Finance. Edited by Richard A. Musgrave and Alan T. Peacock. London: Palgrave Macmillan, ISBN 978-0-333-61355-9.

Zhang, Xiaoling, and Yue Wang. 2017. How to reduce household carbon emissions: A review of experience and policy design considerations. Energy Policy 102: 116-24. [CrossRef]

Publisher's Note: MDPI stays neutral with regard to jurisdictional claims in published maps and institutional affiliations. 